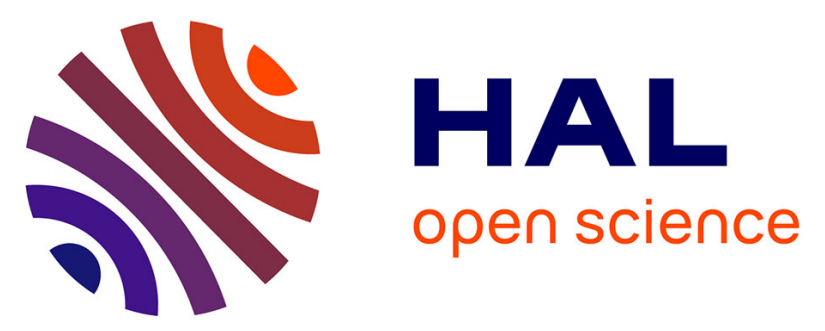

\title{
Encephalopathic attacks in a family co-segregating myotonic dystrophy type 1 , an intermediate Charcot-Marie-Tooth neuropathy and early hearing loss
}

Frank Spaans, Carin G Faber, Hubert J M Smeets, Paul a M Hofman, Claudia Braida, Darren G Monckton, Christine E M de Die

\section{To cite this version:}

Frank Spaans, Carin G Faber, Hubert J M Smeets, Paul a M Hofman, Claudia Braida, et al.. Encephalopathic attacks in a family co-segregating myotonic dystrophy type 1 , an intermediate CharcotMarie-Tooth neuropathy and early hearing loss. Journal of Neurology, Neurosurgery and Psychiatry, 2009, 80 (9), pp.1029. 10.1136/jnnp.2008.170126 . hal-00552756

\section{HAL Id: hal-00552756 \\ https://hal.science/hal-00552756}

Submitted on 6 Jan 2011

HAL is a multi-disciplinary open access archive for the deposit and dissemination of scientific research documents, whether they are published or not. The documents may come from teaching and research institutions in France or abroad, or from public or private research centers.
L'archive ouverte pluridisciplinaire HAL, est destinée au dépôt et à la diffusion de documents scientifiques de niveau recherche, publiés ou non, émanant des établissements d'enseignement et de recherche français ou étrangers, des laboratoires publics ou privés. 
Encephalopathic attacks in a family co-segregating myotonic dystrophy type 1, an intermediate Charcot-Marie-Tooth neuropathy and early hearing loss

F Spaans ${ }^{1}$, C G Faber ${ }^{2}$, H J M Smeets ${ }^{3}$, P A M Hofman ${ }^{4}$, C Braida ${ }^{5}$, D G Monckton ${ }^{5}$, C E $\mathrm{M}$ de Die-Smulders ${ }^{6}$

${ }^{1}$ Department of Clinical Neurophysiology, ${ }^{2}$ Department of Neurology, ${ }^{4}$ Department of

Radiology, ${ }^{6}$ Department of Clinical Genetics, Maastricht University Medical Centre, Maastricht, The Netherlands

${ }^{3}$ Department of Genetics and Cell Biology, Maastricht University, Maastricht, The Netherlands

${ }^{5}$ Molecular Genetics, Faculty of Biomedical and Life Sciences, University of Glasgow, Glasgow, United Kingdom

Keywords: myotonic dystrophy, Charcot-Marie-Tooth, encephalopathy, hearing loss.

Disclosure: The authors report no conflicts of interest.

Correspondence to:

Prof. F. Spaans

Papenstraat 9, 6211 LG Maastricht, The Netherlands

e-mail: f.spaans@kn.unimaas.nl

telephone: $+31-43-3213784$

fax: $+31-43-3211982$.

Number of words in the text: 3,495

Number of words in the abstract: 248

The Corresponding Author has the right to grant on behalf of all authors and does grant on behalf of all authors, an exclusive licence on a worldwide basis to the BMP Publishing Group Ltd and its licences, to permit this article (if accepted) to be published in JNNP and any other BMJ Group products and to exploit all subsidiary rights, as set in our licence (http://jnnp.bmijournals.com//ifora/licence/pdf). 


\section{ABSTRACT}

Objective: To report new disease components in a unique myotonic dystrophy type 1 (DM1) family previously described by us, in which all affected members also had a sensorimotor neuropathy that co-segregated with markers flanking the DM1 locus.

Methods: Clinical observations, electrophysiology, audiometry, DNA studies.

Results: During a follow-up period of over 25 years, we observed: i) The co-segregation of a striking new encephalopathic phenotype. In middle age, five patients were admitted on multiple occasions with attacks of impaired consciousness, psychomotor agitation, fever and, in about half of the cases, focal neurologic signs, including unilateral weakness, sensory deficits and dysphasia. Reported onset phenomena consisted of confusion, headache, focal neurologic symptoms and nausea; ii) Many patients show an early and severe sensorineural hearing loss; iii) Although they have mothers with the adult onset type, the four affected subjects from the youngest generation do not show any signs or symptoms of childhood or congenital of myotonic dystrophy. iv) The neuropathy meets the criteria of an intermediate type Charcot-Marie-Tooth, and is more severe in the males; and v) Patients presented with an expanded fragment at the DM1 CTG repeat, but this allele was refractory to PCR amplification and triplet repeat primed PCR at the 3' end of the array, indicating the existence of an additional lesion at the 3' end.

Conclusions: The phenotype in this unique family extends beyond myotonic dystrophy and CMT to include encephalopathic attacks and early hearing loss, and is associated with an atypical mutation at the DM1 locus. 
Myotonic dystrophy type 1 (DM1) is the most common form of muscular dystrophy in adults. Besides involvement of skeletal muscles, with mainly facial and distal limb weakness, wasting and myotonia, DM1 patients may have cataract, cardiac abnormalities, endocrine changes, and central nervous system involvement such as daytime somnolence and apathy. ${ }^{1}$ DM1 is dominantly inherited and in 1982 was shown to be linked to chromosome $19 .^{2}$ In 1986, we described 13 family members with clinical and electromyographic features of hereditary motor and sensory neuropathy, eight of them also exhibiting clinical or electromyographic signs of myotonic dystrophy. Genetic linkage studies with markers for chromosomes 1 and 19 strongly suggested that the disorder was caused by a single mutation at the DM1 locus, or by two closely linked mutations, on chromosome $19 .{ }^{3}$ In a follow up study, 10 patients (nine from the original study and one additional patient) and 25 clinically unaffected relatives were investigated using recombinant DNA technology. This analysis confirmed linkage to the DM1 locus (LOD score $=7.04$, theta $=0$ ) and excluded linkage to the chromosome 17 Charcot-Marie-Tooth neuropathy type 1 (CMT1) locus. ${ }^{4}$ This previous study was completed one year before the discovery of an unstable CTG repeat expansion in the DMPK gene at chromosome 19q13.3. ${ }^{1}$ In the present paper we report on new atypical disease components and genetic studies in this unique DM1 family.

\section{PATIENTS AND METHODS}

\section{Patients}

During a 25 year follow up in the affected family (Figure 1) information was collected through history taking, physical examinations, clinical observations, electrophysiologic and audiologic investigations, and DNA studies. All investigations were performed in the context of regular patient care. Written informed consent was obtained from all patients described in the present article; for a deceased patient consent was given by a direct relative.

\section{Electrophysiologic studies}

Motor and sensory nerve conduction studies were performed in a standard manner with surface electrodes for both stimulation and recording. Skin temperature over the nerve was at least $32^{\circ} \mathrm{C}$. Needle electromyography (EMG) was performed with concentric needle electrodes. Electroencephalographic (EEG) studies were recorded with scalp electrodes according to the international $10-20$ system. 


\section{Hearing function}

Pure-tone audiograms of four affected subjects were available. In other subjects, early hearing loss was considered present or absent based on history taking.

\section{Genetic studies}

Peripheral blood DNA was analysed for expansion of the DM1 CTG repeat by Southern blot hybridisation of Hindlll restricted genomic DNA ${ }^{5}$, Southern blot hybridisation of PCR amplified alleles ${ }^{6}$ and triplet-primed PCR. ${ }^{7}$ Analysis of the $1.5 \mathrm{Mb}$ PMP22 duplication and DNA sequencing of GJB1, CACNA1A, ATP1A2 and NOTCH3 was performed as described. ${ }^{8-12}$ Cytogenetic analysis of GTG-banded chromosomes at the 550 band level and FISH analysis with probes 2J15, 2525J15, 569M1, 118G62, 1435M10, 1490623, specific for chromosome band 19q13 and probes specific for the subtelomeric regions of chromosome 19p and 19q, was performed as described. ${ }^{1314}$ LOD scores were calculated using Superlink. ${ }^{15}$

\section{RESULTS}

\section{General clinical data}

All 14 affected members of the family presented with symptoms of both DM1 and CMT (Table 1).

Generation I. I-6 and I-9 were invariably described by their offspring as having no motor disability. The man was strong and worked as a farmer and butcher until he died at the age of 79; his wife lived until the age of 85 years.

Generation II. All affected members in this generation were women and lived from 65 to 91 years. II-26 could not be examined, but was defined as an obligate carrier of both DM1 and CMT since her son, III-12, had a severe adult type DM1 and abnormal nerve conduction. II-28 developed recurrent encephalopathic attacks (see below).

Generation III. After 1991 we lost contact with patient III-1. At that time, her nerve conduction was moderately abnormal, but clinical signs of muscle pathology were lacking. ${ }^{4}$ Muscle atrophy was most progressive in III-7 and III-12, ${ }^{3}$ who died at ages 52 and 46, respectively. At age 51 a complete right-sided bundle-branch block was recorded in III9 and at age 64 a first grade atrio-ventricular block was found in III-17. From about age 50, III-9, III-16 and III-17 showed recurrent encephalopathic attacks (see below).

Generation IV. In this generation the four children of III-16 and III-17 are affected. Compared with their mothers, the CMT component of the disorder is much more 
Table 1. Main clinical data with respect to DM1 and CMT

\begin{tabular}{|c|c|c|c|c|c|c|c|c|c|c|c|c|c|c|}
\hline Patient & II-24 & $11-25$ & II-27 & II-28 & III-1 & III-7 & III-9 & III-12 & III-16 & III-17 & IV-19 & IV-20 & IV-21 & IV-22 \\
\hline Year of birth & 1908 & 1910 & 1913 & 1914 & 1936 & 1933 & 1947 & 1940 & 1944 & 1947 & 1968 & 1971 & 1976 & 1978 \\
\hline Gender & $\mathrm{F}$ & $\mathrm{F}$ & $\mathrm{F}$ & $\mathrm{F}$ & $\mathrm{F}$ & M & M & M & $\mathrm{F}$ & $\mathrm{F}$ & M & M & M & $\mathrm{F}$ \\
\hline Clinical myotonia & - & + & - & ++ & - & + & + & + & \pm & - & + & + & - & - \\
\hline Myotonic discharges & + & ++ & ++ & +++ & - * & +++ & +++ & +++ & + & + & + & + & + & - ** \\
\hline Cataract & $L / R$ & $\mathrm{~L}$ & $L / R$ & $L / R$ & $L / R^{\text {irop }}$ & $L / R^{\text {irop }}$ & $L / R$ & $L / R^{\text {irop }}$ & $L / R$ & $L / R$ & $L / R^{i}$ & - & n.i. & $L / R$ \\
\hline surgery at age & $65 / 78$ & 63 & $-/-$ & $55 / 55$ & ? & $-/-$ & $46 / 47$ & $-/-$ & $47 / 44$ & $47 / 47$ & $37 / 37$ & & & $26 / 26$ \\
\hline $\begin{array}{l}\text { Distal weakness and/or } \\
\text { muscle atrophy } \\
\text { first noticed about age }\end{array}$ & - & $\begin{array}{c}+ \\
50\end{array}$ & - & $\begin{array}{c}+ \\
55\end{array}$ & - & $\begin{array}{l}+ \\
25\end{array}$ & $\begin{array}{c}+ \\
27\end{array}$ & $\begin{array}{c}+ \\
18\end{array}$ & $\begin{array}{c}+ \\
52\end{array}$ & $\stackrel{+}{44}$ & $\begin{array}{c}+ \\
16\end{array}$ & $\begin{array}{c}+ \\
17\end{array}$ & $\begin{array}{c}+ \\
19\end{array}$ & $\begin{array}{l}+ \\
24\end{array}$ \\
\hline $\begin{array}{l}\text { Sensory disturbances } \\
\text { at the feet }\end{array}$ & + & \pm & + & \pm & - & + & + & + & - & + & + & + & ? & + \\
\hline Absent ankle jerks & + & + & - & + & - & + & + & + & - & + & + & + & + & + \\
\hline Pes cavus & - & - & - & - & - & + & + & - & \pm & - & ++ & \pm & - & + \\
\hline $\begin{array}{l}\text { Abnormal nerve } \\
\text { conduction (> Table 2) }\end{array}$ & + & + & + & + & + & + & + & + & + & + & + & + & + & + \\
\hline
\end{tabular}

${ }^{*}=$ at age $51 ;{ }^{* *}=$ at age $10 ; L / R^{\text {irop }}=$ bilateral only iridescent opacities; n.i. = not investigated

pronounced. From early puberty, all four, but particularly the three males, developed atrophy of the lower leg and hand muscles with distal weakness and areflexia. IV-19 is the most severely affected patient of his generation. On physical examination in 2006, at age 37 , he had claw hands, almost complete paralysis of distal leg muscles, moderate proximal weakness, and weakness of neck and respiratory muscles. In 2007 he had his first encephalopathic attack (see below). At age 18, IV-21 had to be reanimated because of ventricular fibrillation and subsequently received an internal cardiac defibrillator. All four patients of generation IV are intelligent and energetic. They obtained university degrees and, despite their physical handicap, acquired skilled jobs commensurate with their academic training.

\section{Needle EMG and nerve conduction studies}

At the time of the previous study, ${ }^{4}$ III-1 (age 51) and IV-22 (age 10) showed no myotonic discharges. They were not available for re-examination. In all other patients myotonic discharges were found at their most recent EMG study. All 14 affected members presented with abnormal nerve conduction (Table 2). Mean values of median nerve motor conduction velocities were for the men $33 \mathrm{~m} / \mathrm{s}(\mathrm{n}=6)$, women $40 \mathrm{~m} / \mathrm{s}(n=8)$, and all 
Table 2. Nerve conduction data in the affected family members

\begin{tabular}{lcccccccccccccc}
\hline Patient & II-24 & II-25 & II-27 & II-28 & III-1 & III-7 & III-9 & III-12 & III-16 & III-17 & IV-19 & IV-20 & IV-21 & IV-22 \\
\hline Age at examination & 68 & 65 & 63 & 59 & 51 & 42 & $54^{\star}$ & 43 & 44 & $41^{\star}$ & 20 & $24^{\star}$ & $22^{\star}$ & 10 \\
Gender & F & F & F & F & F & M & M & M & F & F & M & M & M & F \\
Median MNCV & 40 & 38 & 45 & 31 & 48 & 27 & 39 & 42 & 44 & 33 & 39 & 23 & 27 & 44 \\
Peroneal MNCV & 32 & 29 & 33 & NR & 34 & NR & NR & $21^{\star \star}$ & 33 & 26 & NR & $13^{\star \star}$ & NR & 26 \\
Median SNCV & 42 & NRE & 43 & NR & 49 & NR & NRE & 47 & 43 & NR & NRE & NR & NR & 42 \\
Sural SNCV & NR & NR & 30 & NR & NR & NR & NR & NR & NR & NR & NR & NR & NR & NR \\
\hline
\end{tabular}

MNCV = motor nerve conduction velocity $(\mathrm{m} / \mathrm{s}) . \mathrm{SNCV}=$ sensory nerve conduction velocity $(\mathrm{m} / \mathrm{s})$. Median NCVs were measured over the elbow-wrist segment, peroneal MNCVs over the kneeankle segment and sural SNCVs between ankle and calf over a $12 \mathrm{~cm}$ segment. NR = no response with distal nerve stimulation. NRE $=$ no response with nerve stimulation at the level of the elbow. * $=$ data obtained at re-examinations after the previous publications. ${ }^{* *}=$ the negative peak of the relevant CMAP was lower than $0.5 \mathrm{mV}$, which means that this MNCV value does not reliably represent the degree of demyelination. ${ }^{16}$

patients $37 \mathrm{~m} / \mathrm{s}$. These values are characteristic of intermediate type CMT. ${ }^{17} 18$ Sensory deficits were limited to the feet, even when no sensory nerve action potentials could be obtained on distal stimulation of the median nerve.

\section{Recurrent encephalopathic attacks}

Encephalopathic attacks occurred in II-28, III-9, III-16 and III-17 from about age 50 and in IV-19 from age 39. They consisted of confusion, decreased consciousness, psychomotor agitation and fever, and were often accompanied by transient unilateral weakness and/or other focal neurological symptoms, but only rarely with visual symptoms. Table 3 presents an overview of attacks leading to hospital admission. For minor attacks, with or without focal signs and of limited duration (some minutes to half a day), often no doctor was consulted. Intervals between attacks varied from one week to many months. Most attacks started with headache, which could be severe, but none of these five patients had a migraine history. Only IV-22 has typical migraine attacks with aura, but migraine also occurs in her father's family. Decreased consciousness could be accompanied by repelling or phobic behaviour, assuming a foetal position, and hallucinations. On all admissions there was fever lasting one to four days, but physical examination and laboratory tests, including total blood counts, glucose levels, electrolytes, renal and liver functions, 
Table 3. Acute encephalopathic presentations; onset phenomena and findings on hospital admission.

\begin{tabular}{|c|c|c|c|c|c|c|c|c|c|c|c|c|c|c|}
\hline \multirow{2}{*}{$\begin{array}{l}\text { Signs and } \\
\text { symptoms }\end{array}$} & II-28 & II-28 & III-9 & III-9 & III-9 & III-9 & III-16 & III-16 & III-16 & III-17 & III-17 & III-17 & IV-19 & IV-19 \\
\hline & 58 & 66 & 49 & 51 & 54 & 56 & 57 & 59 & 64 & 50 & 57 & 59 & 39 & 40 \\
\hline Admissions & 1973 & 1981 & 1996 & 1999 & 2002 & 2004 & 2001 & 2003 & 2008 & 1998 & 2005 & $2007 \#$ & $2007 \#$ & 2008 \\
\hline \multicolumn{15}{|l|}{ Onset phenomena: } \\
\hline Headache & $?$ & $?$ & + & + & $?$ & + & + & + & - & + & - & + & $?$ & + \\
\hline Confusion & + & + & + & + & + & + & + & + & + & + & + & + & $?$ & + \\
\hline $\begin{array}{l}\text { Other reported onset } \\
\text { phenomena }\end{array}$ & $L$ leg $m+s$ & $\begin{array}{l}\text { non- } \\
\text { reactive }\end{array}$ & $\begin{array}{l}\text { feeling } \\
\text { ill }\end{array}$ & $\begin{array}{l}\text { feeling } \\
\text { ill }\end{array}$ & $\begin{array}{l}\text { wording } \\
\text { problems }\end{array}$ & $\begin{array}{l}\text { wording } \\
\text { problems }\end{array}$ & $\begin{array}{l}\text { L face }+ \\
\text { limbs } s\end{array}$ & $\begin{array}{l}\mathrm{R} \text { hand } \\
\mathrm{s}\end{array}$ & $\begin{array}{l}\text { feeling ill } R \\
\text { face } m\end{array}$ & $\begin{array}{c}\mathrm{R} \\
\text { arm } \\
\mathrm{m}\end{array}$ & $\begin{array}{l}\text { apathy } \\
\text { vomiting }\end{array}$ & $\begin{array}{c}\text { feeling } \\
\text { ill } \\
\text { vomiting }\end{array}$ & $\begin{array}{l}\text { non- } \\
\text { reactive }\end{array}$ & feeling ill \\
\hline \multicolumn{15}{|l|}{ Findings on admission: } \\
\hline Impaired consciousness & coma* $^{*}$ & coma* $^{*}$ & + & + & coma* $^{*}$ & + & + & stupor* & + & + & + & + & + & + \\
\hline Psychomotor agitation & + & + & + & + & + & + & + & + & + & + & - & + & + & - \\
\hline Body temperature $\left({ }^{\circ} \mathrm{C}\right)$ & 38.3 & 38.9 & 39.5 & 40.0 & 39.2 & 40.0 & 38.2 & 39.5 & 38.5 & 38.9 & 40.2 & 38.1 & 39.4 & 38.5 \\
\hline Focal neurologic signs & $\underset{\mathrm{m}+\mathrm{S}}{\mathrm{L} \text { arm }+ \text { leg }}$ & $\begin{array}{c}R \text { arm } \\
m+s\end{array}$ & - & - & - & $\begin{array}{l}\mathrm{R} \text { face } \mathrm{m} \\
\text { dysphasia }\end{array}$ & dysphasia & - & $\begin{array}{l}\text { R face }+ \\
\text { arm m }\end{array}$ & - & dyphasia & - & - & dyphasia \\
\hline Meningism & - & - & + & - & - & - & - & + & \pm & + & + & - & ++ & - \\
\hline EEG: most abnormal side & i.a. & L & n.p. & L & $\mathrm{R}$ & L & L & $\mathrm{R}$ & L & $\mathrm{R}$ & L & n.p. & n.p. & L \\
\hline
\end{tabular}

$?=$ unknown; $\mathrm{m}$ = motor deficit; $\mathrm{s}=$ sensory symptoms; * = initially; \# = admission elsewhere; i.a.= insufficiently assessable due to massive artefacts; n.p. $=$ not performed 

CSF protein and glucose, CSF cell counts, blood and CSF cultures, never yielded an explanation for the fever or mental obtundation. Oxygen saturation, measured during three admissions of III-9, was found to be normal. At the first admission of III-16, serum lactate was found to be normal and urine tests for porphyria were negative. Muscle biopsies formerly taken from III-7 and III-9, ${ }^{3}$ were reassessed recently (sections stained for oxidative enzymes and EM studies on preserved plastic embedded material) and did not reveal signs of mitochondrial disease. All EEGs recorded in the acute phase showed severe asymmetric abnormalities (Table 4, Figure 2).

Table 4. Main EEG findings after hospital admission in affected subjects with encephalopathic attacks.

- Unilateral suppression of normal background activity.

- Intermittent rhythmic delta activity, maximal over the temporal regions of the same hemisphere.

- Bilateral frontal intermittent rhythmic delta activity, often with higher amplitudes on the most abnormal side.

- Slowing of preserved posterior dominant rhythm as compared to follow-up EEGs.

- Diffuse irregular theta-delta activity dominating on the most abnormal side.

- In a single recording, sharp and triphasic waves over the anterior brain areas, with predominance over the most affected hemisphere, but no typical epileptiform activity.

- No alternation of the most abnormal side during a single hospitalisation, but frequently so in a new confusional episode (see also Table 3 ).

MRI studies performed in III-9, III-16, III-17 and IV-19 showed only slight to moderate white matter lesions that are known to occur in DM1 adults ${ }^{19}$ (Figure 3). Focal neurologic deficits always disappeared within a few days and complete clinical recovery usually occurred within one to two weeks. However, in 2008 III-16 was hospitalised for almost two months because she remained confused, anxious and hallucinatory. Despite antipsychotic medication, this picture only slightly improved during her hospital stay. In September 2007, IV-19 was found unconscious in the doorway of his flat. On admission 
to his local hospital he was somnolent, feverish and showed neck stiffness, but no focal neurological deficits. Because CSF was normal, he was diagnosed with viral meningitis and treated with aciclovir. He was also treated with antibiotics for a possible lung infection. However, even in this case, laboratory tests, including blood and CSF cultures, showed no indications of an infectious disorder. Because of hallucinations, IV19 was also treated with haloperidol. After three weeks he was discharged from the local hospital. When he was seen at our neurology outpatient department more than two months later, he still had considerable memory and concentration problems and an EEG showed distinct bilateral slow wave abnormalities in the temporal regions, as well as signs of brainstem involvement. In September 2008 he was admitted to our hospital with a less severe attack (Table 3).

\section{Early hearing loss}

For generation II, hearing loss before age 45 in II-26, II-27 and II-28 was reported by relatives. No information on hearing problems was available for III-1 and III-7. Obvious hearing loss was reported, by the patients themselves or by their relatives, to be present in III-9 from about age 43, and in III-12, III-16, and III-17 when they were teenagers. Some high-frequency loss was observed in IV-19 at age 20 at a general physical examination. There were no indications of obvious noise exposure, and unaffected family members noticed no early onset hearing loss.

Table 5. Data from pure-tone audiograms obtained in four of the affected family members

\begin{tabular}{|c|c|c|c|c|c|c|c|c|c|c|c|c|c|c|c|}
\hline \multirow{3}{*}{ Patient } & \multirow{3}{*}{$\begin{array}{l}\text { Age } \\
\text { years }\end{array}$} & \multicolumn{14}{|c|}{ Hearing loss in $\mathrm{dB}$} \\
\hline & & \multicolumn{7}{|c|}{ Right ear } & \multicolumn{7}{|c|}{ Left ear } \\
\hline & & 0.25 & 0.5 & 1 & 2 & 4 & 8 & $\mathrm{kHz}$ & 0.25 & 0.5 & 1 & 2 & 4 & 8 & $\mathrm{kHz}$ \\
\hline III-9 & 51 & 30 & 50 & 65 & 80 & 105 & 100 & & 10 & 15 & 45 & 75 & 90 & 80 & \\
\hline III-16 & 43 & 0 & 0 & 70 & 90 & 90 & $>100$ & & 20 & 15 & 70 & 95 & 100 & $>100$ & \\
\hline III-17 & 35 & 10 & 5 & 5 & 60 & 70 & 75 & & 5 & 5 & 5 & 65 & 85 & 80 & \\
\hline $\mathrm{III}-17^{*}$ & 42 & 10 & 10 & 5 & 65 & 95 & 100 & & 10 & 10 & 10 & 65 & 95 & 95 & \\
\hline IV-19 & 38 & 20 & 10 & 25 & 60 & 75 & 90 & & 5 & 5 & 20 & 50 & 70 & 85 & \\
\hline
\end{tabular}

* Following this test, short-latency brainstem auditory evoked potentials were measured. Both stimulation of the right ear and of the left ear showed normal I-V interpeak latencies (4.2 ms and $4.3 \mathrm{~ms}$, respectively). 
Audiologic studies performed in four patients showed severe to profound bilateral sensorineural hearing loss, clearly in excess of that expected for their age (Table 5).

\section{Genetic studies}

Conventional Southern blot analysis of restriction digested genomic DNA revealed a variable expanded allele of 600 to $1,200 \mathrm{bp}$ at the DMPK locus in all affected family members investigated (II-27, III-9, III-16, III-17, IV-19, IV-20, IV-21 and IV-22) that was not present in the two unaffected children, IV-11 and IV-12, of III-9. However, the mutant allele was not PCR amplifiable, even using very sensitive small pool $\mathrm{PCR}^{6}$ approaches. These amplification procedures are extremely robust and we routinely PCR amplify DM1 alleles in excess of 1,000 CTG repeats; much larger than the expansion detected by Southern blot analysis in this family. PCR was repeated with multiple different non-overlapping primers on each side of the repeat array, excluding a simple sequence variant in one of the primer sites. Similarly, triplet repeat primed-PCR (TP-PCR) from within the CTG array to flanking primers, ${ }^{7}$ was found to be positive for a CTG expansion at the 5' end of the array, but negative for a CTG expansion at the 3' end. The 3' end TP-PCR was consistently negative when repeated using multiple alternative non-overlapping flanking primers. These data reveal the existence of an additional lesion at the 3' end of the CTG repeat expansion in this family. However, chromosome analysis in III-9 and III-16, revealed no defects, including no pericentric or paracentric inversions, or deletions of the $19 q 13$ or subtelomeric regions.

To rule out other potential causes of CMT or acute encephalopathy, several other candidate genes were screened for mutations in at least one affected individual. These analyses excluded duplication of the PMP22 gene in III-17, and a mutation in the coding region of GJB1 gene (also known as connexin 32) in IV-21, the two most common causes of CMT. ${ }^{89}$ We also found no mutations in III-16 in the coding regions of the CACNA1A and ATP1A2 genes associated with the two most common forms of familial hemiplegic migraine (FHM), types 1 and $2 .^{10}{ }^{11}$ Mutations clustered in exon four of NOTCH3 cause cerebral autosomal dominant arteriopathy with subcortical infarcts and leukoencephalopathy (CADASIL). ${ }^{12}$ No mutations were found in exon four of NOTCH3 in III-9.

\section{DISCUSSION}

\section{Encephalopathic presentations}




\section{Diagnostic considerations}

Evidence of central nervous system involvement is not rare in patients with DM1.

Daytime somnolence and apathy occur frequently, and psychologic, electrophysiologic, neuropathologic and imaging studies have shown functional and structural brain abnormalities. ${ }^{1}$ However, acute encephalopathic presentations like those observed in five of the affected family members described here have not been reported before. Similar episodes are known to occur in acute confusional migraine (ACM), CADASIL, and familial hemiplegic migraine (FHM). Besides confusion and agitation, in some cases of ACM transient focal neurological deficits have been reported. ${ }^{20}$ However, ACM almost exclusively occurs in children and adolescents, ${ }^{21}$ and although in the majority of cases there is a family history of migraine ${ }^{2021}$ a monogenic occurrence of ACM as such has not been described.

The development of CADASIL may be preceded for many years by attacks of migraine with aura. ${ }^{22}$ Some CADASIL patients develop attacks with confusion and decreased consciousness, often accompanied by fever, asymmetric neurological deficits and contralateral EEG abnormalities. ${ }^{23}$ However, in our patients MRI studies did not show characteristic CADASIL features, ${ }^{24}$ and screening of $\mathrm{NOTCH}^{12}$ was negative.

FHM is an autosomal dominant subtype of migraine with aura. Despite what 'hemiplegic' suggests, loss of strength may be partial and may be confined to a single limb. ${ }^{25}$ Besides unilateral motor weakness, the aura includes at least one of the following components: sensory symptoms, visual symptoms or dysphasia. ${ }^{25}$ Attacks with confusion, impaired consciousness, sometimes even coma, and also fever, have been reported in FHM, and EEG findings are similar to those in our cases. ${ }^{26}{ }^{27}$ However, in two large series of FHM patients the mean age at onset was found to be $\sim 15$ years, and visual aura symptoms occurred in most attacks. ${ }^{25} 27$ In contrast, in the present family age at onset was in middle age, visual onset phenomena were exceptional, and in many attacks headache was one of the onset phenomena. Moreover, screening of the two genes most commonly mutated in FHM was negative.

\section{Pathophysiologic aspects}

The occurrence of decreased consciousness and fever in our patients, as well as in a minority of patients with $\mathrm{FHM}$, is obviously due to brain stem involvement. It is known that cerebral disorders (e.g. stroke ${ }^{28}$ and traumatic injury ${ }^{29}$ ) may cause 'neurogenic fever'. Some case reports describe the occurrence of fever attacks as a symptom of 
epilepsy, which is thought to be due to spreading of the epileptic activity to the anterior hypothalamus. ${ }^{3031}$ Similarly, propagation of cortical spreading depression, which is known to be responsible for migraine auras, to the brainstem may explain the fever and decreased consciousness in FHM. Whether such a mechanism also underlies the symptoms in the present family remains uncertain because the onset symptoms of attacks showed no clear gradual development and progression.

\section{EEG abnormalities}

All EEGs recorded in the acute phase of the attacks were characterised by pronounced asymmetric abnormalities. Focal neurological signs during hospital observation were always contralateral to the most abnormal side of the EEG. Remarkably, this was not always the case with the onset phenomena reported by III-16 at both admissions and by III-17 at her first admission (Table 3). Both patients and their husbands were certain about the symptomatic side. Therefore, it seems that during the initial phase of the attack, alternation of the most involved hemisphere may occur. Also when unilateral signs or symptoms were lacking, EEGs showed distinct asymmetric abnormalities. Intermittent rhythmic delta activity is primarily associated with cortical and subcortical grey matter abnormalities, and is likely to appear when brain dysfunction is actively fluctuating, progressing or resolving, and widespread. ${ }^{32}$

\section{Intermediate CMT neuropathy}

On the basis of electrophysiological and histopathological criteria, CMT is divided into two major entities, the demyelinating (CMT1) and axonal (CMT2) forms. The electrophysiologic criterion consists of motor conduction velocities (MCV) of the median nerve: $<38 \mathrm{~m} / \mathrm{s}$ in CMT1 and $>38 \mathrm{~m} / \mathrm{s}$ in CMT2. However, a third type with both demyelinating and axonal features and intermediate median nerve MCVs is increasingly recognised. In this intermediate CMT (ICMT), median nerve MCVs are in the range of 25 to $45 \mathrm{~m} / \mathrm{s}^{17}$ As previously reported, ${ }^{3}$ the main abnormalities observed in sural nerve biopsies from patients of the present family were loss of large myelinated fibres, clusters of myelinated fibres usually within small onion bulb formations, and isolated fibres with disproportionately thin myelin sheaths. Both these histopathological findings, and the results of the nerve conduction studies (Table 2), meet the ICMT features as described in autosomal dominant intermediate (DI-CMT) and X-linked (CMTX1) CMTs. ${ }^{17} 18$

\section{Early hearing loss}


Hearing is not commonly impaired to a significant or symptomatic degree in adults with DM1. ${ }^{1}$ One well documented study, however, found high frequency hearing loss in the pure-tone audiogram in seven of 13 unselected and unrelated DM1 patients, which was significantly abnormal for their age ('precocious presbyacusis'). ${ }^{33}$ In the present family a clinically obvious hearing loss before age 45 was present in most patients in generation II and III, in three of them as early as childhood. Early hearing loss was also recorded in the eldest individual in generation IV. The results of the pure-tone audiograms performed in four patients (Table 5) reveal greater abnormalities than previously reported in $\mathrm{DM} 1 .^{33}$ It seems likely that early sensorineural hearing loss is part of the unique syndrome in the present family.

\section{Genetic aspects}

All 14 affected family members now examined have presented with features of DM. The DM symptoms segregate with markers flanking the DM1 locus (LOD score $=7.03$, theta $=0)^{4}$ and eight of the patients have tested positive for an expansion in the DMPK gene as evidenced by Southern blot hybridisation and TP-PCR at the 5 ' end of the array. This molecular diagnosis is entirely consistent with the presence in this family of classic DM1 symptoms such as myotonia and cataracts. As is also frequently observed in DM1 families, ${ }^{1}$ there were no signs of the disorder in generation I, late adult onset in generation II, and an even younger age at onset and more severe symptomatology in generation III. However, in generation IV signs of childhood or congenital DM1, which might be expected in the context of the anticipation cascade and maternal transmission, ${ }^{1}$ were lacking. Indeed, all four patients in generation IV are remarkably intelligent and energetic. Moreover, despite appearing by Southern blot analysis of restriction digested genomic DNA to be relatively small ( 600 to 1,200 bp), the mutant allele could not be PCR amplified using our well established, highly robust and sensitive approach to amplifying even large DM1 alleles. ${ }^{6}$ Likewise, TP-PCR failed to reveal a CTG expansion at the 3' end of the array. These data indicate that as well as the classic DM1 CTG expansion, these patients carry an additional lesion at the 3' end of the array. By analogy to the secondary mutations observed in E. coli containing large expanded CTG tracts ${ }^{34}$ and in fragile $X$ syndrome families with expanded CGG tracts, ${ }^{35}$ this lesion might be a deletion or rearrangement of the flanking DNA, or alternatively a modification or insertion into the CTG repeat array. These secondary mutations could modify the 
expression of DMPK and/or other genes in the vicinity and explain the presence of CMT and acute encephalopathy.

In addition to DM1, all 14 affected individuals have clear signs of CMT. No patients have either DM1 or CMT alone. The two disorders thus co-segregate together through 15 meioses yielding a LOD score of 8.03 (theta $=0$ ) to each other. These data strongly suggest that the two disorders are caused by a single, or two very closely linked, mutation(s) on chromosome 19. Although all transmissions where the sex of parent can be defined are maternal in origin, CMTX1 was excluded by sequencing of GJB1 in IV-21 and the failure of III-9 to transmit CMT to his daughter IV-11. Similarly, the absence of linkage to the Duffy locus, ${ }^{4}$ virtually excludes a mutation of $M P Z$ (also known as $P O$ ) as the cause of the CMT since the Duffy locus is less than $2 \mathrm{Mb}$ from MPZ. Moreover, MPZ mutations are associated with CMT phenotypes distinctly different from that in the present family. ${ }^{36}$ Recently, one form of autosomal DI-CMT has been found to be caused by mutations in the DNM2 gene on the short arm of chromosome $19 .^{37}$ However, the genetic distance between DMPK and DNM2 is $36 \mathrm{cM}$ and co-segregation of a mutation in DNM2 in this family is highly improbable. Furthermore, the existence of a single disease causing mutation associated with the genetically unstable DM1 CTG repeat, provides a plausible explanation for the absence of CMT symptoms in the first generation, and the increasingly severe CMT observed in generation IV.

Acute encephalopathy is observed in five members of the family, and assuming it is inherited as a dominant condition, must display incomplete penetrance as the symptoms were not known to be present in II-25 and II-27. Nonetheless, it still segregates with the DM1/CMT phenotype, suggesting that the most probable explanation is that also the encephalopathy is also caused by an atypical DM1 mutation. Likewise, the early hearing loss is incompletely penetrant, but also segregates with the DM1/CMT phenotype. The presence of an atypical DM1 expansion in a family cosegregating an atypical DM1 phenotype (i.e. DM1 with fully penetrant intermediate CMT and reduced penetrance encephalopathy and early hearing loss), strongly suggests that the extended phenotype is attributable to a single molecular lesion at the DM1 locus. Because chromosome analysis showed no abnormalities, the lesion must be submicroscopic. Studies to determine the precise nature of the mutation at the DM1 locus in this unique syndrome are in progress. 


\section{ACKNOWLEDGEMENTS}

We thank all colleagues who contributed to the genetic studies in this family: professor

H. Brunner, Department of Clinical Genetics, Radboud University Medical Centre, Nijmegen (DM1), I. Ginjaar and A. Stam, Department of Human Genetics, University Medical Centre Leiden (NOTCH3, CACNA1A, ATP1A2), professor F. Baas, Department of Neuroscience, Academic Medical Centre, Amsterdam (PMP22, GJB1), and J. Engelen, Department of Clinical Genetics, University Hospital Maastricht (cytogenetic studies). We also thank the colleagues who did the assessments of the muscle biopsies: W. Spliet, Department of Pathology, University Medical Centre Utrecht (enzyme histochemistry), and professor J. Weis, Institute of Neuropathology, University Hospital of the Technical University Aachen (electron microscopy). This work was supported in part by awards to D.G.M. from the Association Française contre les Myopathies, the Myotonic Dystrophy Support Group and the Muscular Dystrophy Campaign.

Competing interests: none declared

\section{REFERENCES}

1. Harper PS. Myotonic Dystrophy, 3rd ed. London: W.B. Saunders; 2001.

2. Whitehead AS, Solomon E, Chambers S, et al. Assignment of the structural gene for the third component of human complement to chromosome 19. Proc Natl Acad Sci USA 1982;79:5021-5.

3. Spaans F, Jennekens FGI, Mirandolle JF, Bijlsma JB, de Gast GC. Myotonic dystrophy associated with hereditary motor and sensory neuropathy. Brain 1986;109:1149-68.

4. Brunner HG, Spaans F, Smeets HJM, et al. Genetic linkage with chromosome 19 but not chromosome 17 in a family with myotonic dystrophy associated with hereditary motor and sensory neuropathy. Neurology 1991;41:80-4.

5. Shelbourne P, Davies J, Buxton J, et al. Direct diagnosis of myotonic dystrophy with a disease-specific DNA marker. N Engl J Med 1993;328:471-5.

6. Monckton DG, Wong LJ, Ashizawa T, et al. Somatic mosaicism, germline expansions, germline reversions and intergenerational reductions in myotonic dystrophy males: small pool PCR analyses. Hum Mol Genet 1995;4:1-8. 
7. Warner JP, Barron LH, Goudie D, et al. A general method for the detection of large CAG repeat expansions by fluorescent PCR. J Med Genet 1996;33:1022-6.

8. Slater $\mathbf{H}$, Bruno D, Ren $\mathrm{H}$, et al. Improved testing for CMT1A and HNPP using multiplex ligation-dependent probe amplification (MLPA) with rapid DNA preparations: comparison with the interphase FISH method. Hum Mutat 2004;24:164-71.

9. Baas, F. Genetic diagnosis of Charcot-Marie-Tooth disease. Methods Mol Biol. 2003;217:77-84.

10. Kors EE, Melberg A, Vanmolkot KR, et al. Childhood epilepsy, familial hemiplegic migraine, cerebellar ataxia, and a new CACNA1A mutation. Neurology 2005;63:1136-7.

11. De Fusco M, Marconi R, Silvestri L, et al. Haploinsufficiency of ATP1A2 encoding the $\mathrm{Na}^{+} / \mathrm{K}^{+}$pump a2 subunit associated with familial hemiplegic migraine type 2. Nat Genet 2003;33:192-6.

12. Obernstein SAJ, Ferrari MD, Bakker E, et al., Diagnostic Notch3 sequence analysis in CADASIL: three new mutations in Dutch patients. Neurology 1999;52:1913-5.

13. Francke U. Digitized and differentially shaded human chromosome ideograms for genetic applications. Cytogenet Cell Genet 1994;65:206-18.

14. Lichter P, Cremer T, Borden J, Manuelidis L, Ward DC. Delineation of individual human chromosomes in metaphase and interphase cells by in situ suppression hybridisation using recombinant DNA libraries. Hum Genet 1988;80:224-34.

15. Silberstein M, Tzemach A, Dovgolevsky N, et al. Online system for faster multipoint linkage analysis via parallel execution on thousands of personal computers. Am J Hum Genet 2006;78:922-35.

16. Franssen H, Vermeulen M, Jennekens FGI. Chronic Inflammatory Neuropathies. In: Emery AEH, editor. Diagnostic Criteria for Neuromuscular Disorders, 2nd ed. Philadelphia: F.A. Davis; 1998:53-9.

17. Verhoeven K, Villanova M, Rossi A, et al. Localization of the gene for the intermediate form of Charcot-Marie-Tooth to chromosome 10q24.1-q25.1. Am J Genet 2001;69:889-94.

18. Senderek J, Hermanns B, Bergmann C, et al. X-linked dominant Charcot-MarieTooth neuropathy: clinical, electrophysiological, and morphological phenotype in four families with different connexin32 mutations. J Neurol Sci 1999;167:90-101. 
19. Di Constanzo A, Di Salle F, Santoro L, Tessitore A, Bonavita V, Tedeschi G. Pattern and significance of white matter abnormalities in myotonic dystrophy type 1: an MRI study. J Neurol 2002;249:1175-82.

20. Pietrini V, Terzano MG, D’Andrea G, Parroni L, Cananzi AR, Ferro-Milone, F. Acute confusional migraine: clinical and electroencephalographic aspects. Cephalalgia 1987;7:29-37.

21. Neinstein L, Milgrom E. Trauma-triggered migraine and acute confusional migraine. $J$ Adolesc Health 2000;27:119-24.

22. Dichgans M, Mayer M, Uttner I, et al. The phenotypic spectrum of CADASIL: clinical findings in 102 cases. Ann Neurol 1998;44:731-9.

23. Schon F, Martin RJ, Prevett M, Clough C, Enevoldson TP, Markus HS. "CADASIL coma": an underdiagnosed acute encephalopathy. J Neurol Neurosurg Psychiatry 2003;74:249-52.

24. O’Sullivan M, Jarosz JM, Martin RJ, Deasy N, Powell JF, Markus HS. MRI hyperintensities of the temporal lobe and external capsule in patients with CADASIL. Neurology 2001;56:628-34.

25. Thomsen LL, Eriksen MK, Roemer SF, Andersen I, Olesen J, Russell MB. A population-based study of familial hemiplegic migraine suggests revised diagnostic criteria. Brain 2002;125:1379-91.

26. Marchioni E, Galimberti CA, Soragna D, et al. Familial hemiplegic migraine versus migraine with prolonged aura: An uncertain diagnosis in a family report. Neurology 1995;45:33-7.

27. Ducros A, Denier C, Joutel A, et al. The clinical spectrum of familial hemiplegic migraine associated with mutations in a neuronal calcium channel. $N$ Engl J Med 2001;345:7-24.

28. Reith J, Jorgensen HS, Pedersen PM, et al. Body temperature in acute stroke: relation to stroke severity, infarct size, mortality, and outcome. Lancet 1996;347:4225.

29. Geffroy A, Bronchard R, Merckx P, et al. Severe head injury in adults: which patients are at risk of early hyperthermia? Intensive Care Med 2004;30:785-90.

30. Semel JD. Complex partial status epilepticus presenting as fever of unknown origin. Arch Intern Med 1987;147:1571-2.

31. Chan KM. Epilepsy - another cause of intermittent fever with confusion. Postgrad Med J 1992:68;119-20. 
32. Sharbrough FW. Nonspecific Abnormal EEG Patterns. In: Niedermeyer E, Lopes da Silva F, editors. Electroencephalography. Basic Principles, Clinical Applications, and Related Fields, 4th ed. Baltimore: Williams \& Wilkins; 1999:215-34.

33. Huygen PLM, Verhagen WIM, Noten JFP. Auditory abnormalities, including 'precocious presbyacusis' in myotonic dystrophy. Audiology 1994;33:73-84.

34. Wojciechowska M, Bacolla A, Larson JE, Wells RD. The myotonic dystrophy type1 triplet repeat sequence induces gross deletions and inversions. J Biol Chem 2005;280:941-52.

35. de Graaf E, Rouillard P, Willems PJ, Smits APT, Rousseau F, Oostra BA. Hotspot for deletions in the CGG repeat region of FMR1 in fragile X patients. Hum Mol Genet 1995;4:45-9.

36. Shy ME, Jáni A, Krajewski K, et al. Phenotypic clustering in MPZ mutations. Brain 2004;127:371-84.

37.Züchner S, Noureddine M, Kennerson M, et al. Mutations in the pleckstrin homology domain of dynamin 2 cause dominant intermediate Charcot-Marie-Tooth disease. Nat Genet 2005;37:289-94. 


\section{Legends}

Figure 1. Pedigree of the affected family. A more extensive pedigree is shown in our 1986 study, and to facilitate comparison, the number code used in that article has been retained here. ${ }^{3}$ Obligate carrier status for some individuals has been defined by their position in the pedigree relative to other affected family members assuming autosomal dominance of all the traits.

Figure 2. Typical EEG pattern during a confusional episode. Recording from III-16 on the third day of her first hospital stay. Above: 10 seconds of EEG showing left-sided suppression of normal background activity and a burst of delta activity mainly over the centrotemporal regions of the left hemisphere as the most prominent abnormalities. Below: a more compressed EEG fragment (30 seconds) reveals the intermittent character of the delta activity (arrows).

Figure 3. Axial T2-weighted image of the brain of patient III-17, aged 57, showing anterior temporal white matter lesions (A). The axial FLAIR image shows confluent periventricular and subcortical white matter lesions, preserving the pyramidal tract (B). MRI of patient III-9 showed similar abnormalities, whereas in patient III-16 WMLs occurred mainly in the temporo-polar areas. Such findings are not unusual in adult DM1 patients. ${ }^{19}$ 

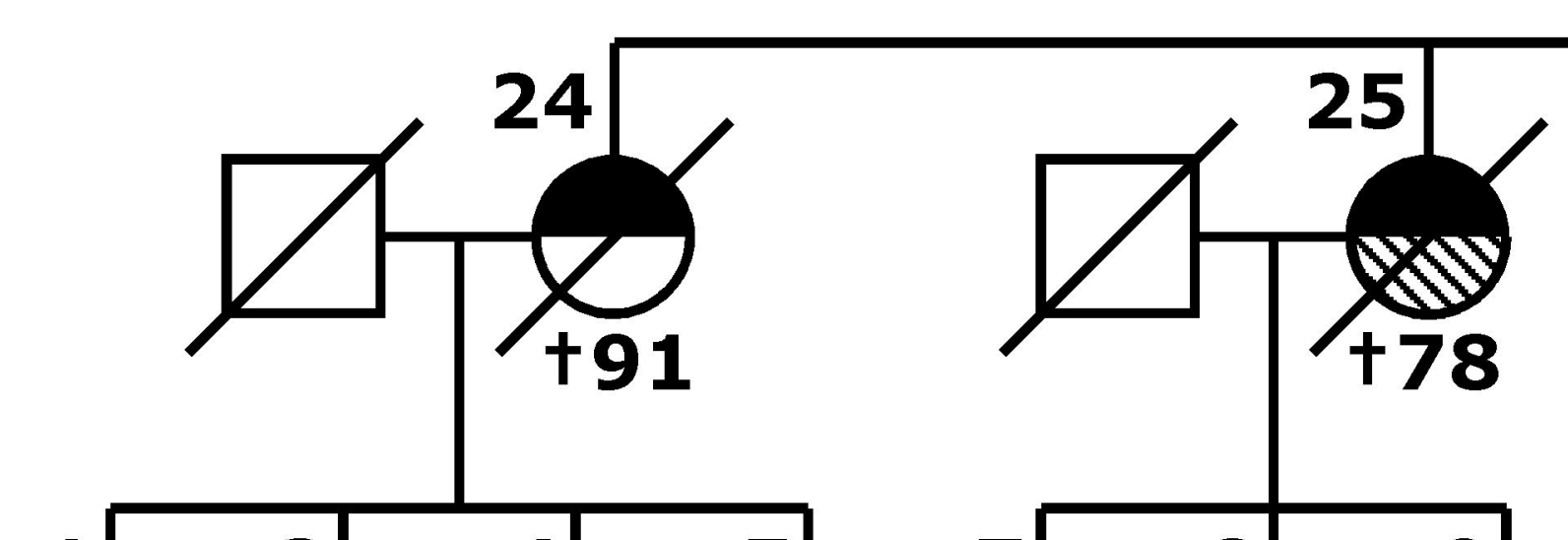

III

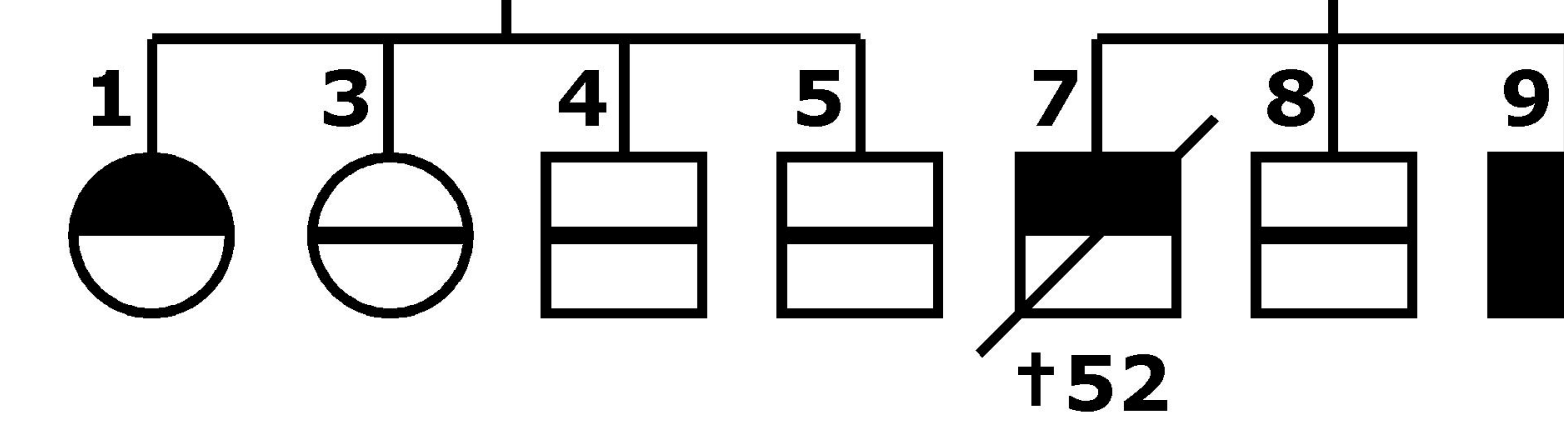

(1)
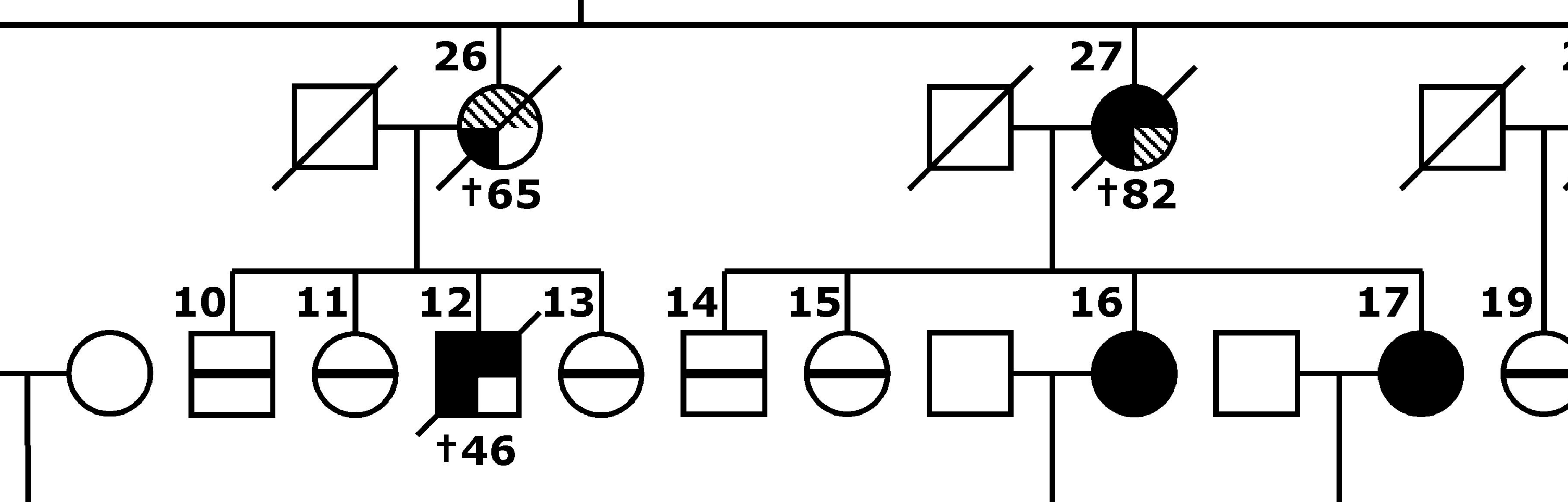

IV
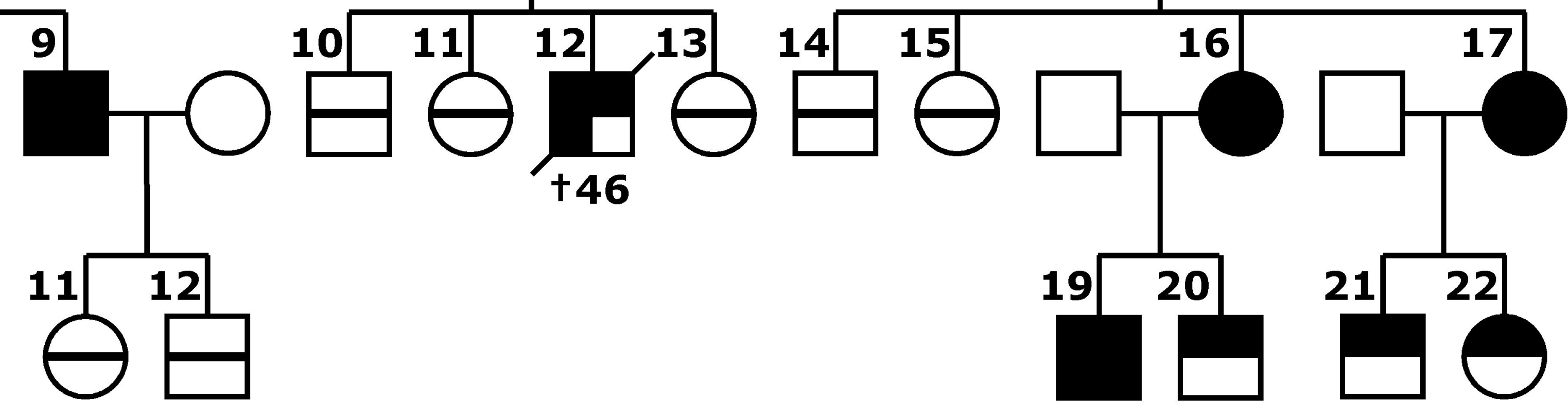

myotonic dystrophy

Charcot-Marie-Tooth

encephalopathic attacks clinically unaffected and normal EMG obligate carrier 


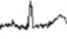

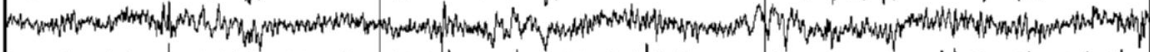

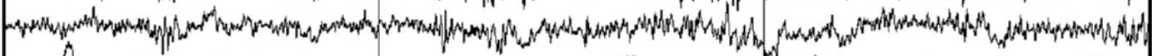

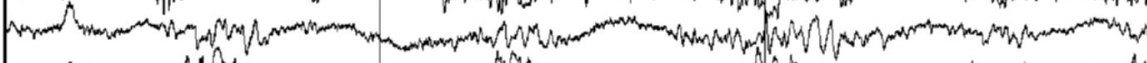

L

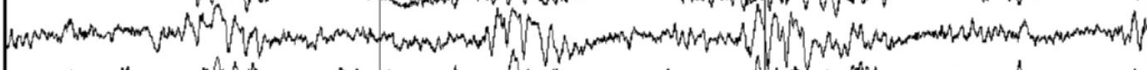

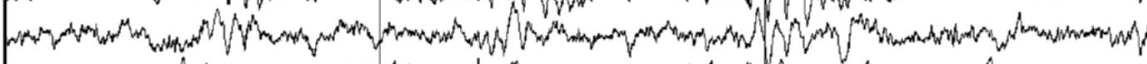

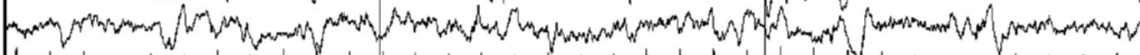

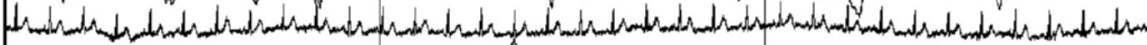

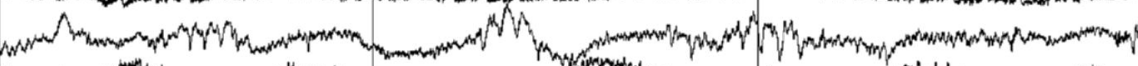

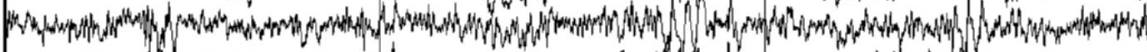

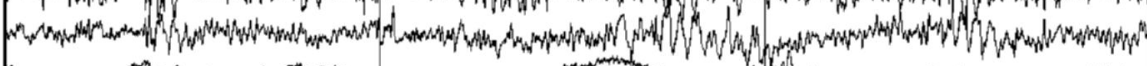
W

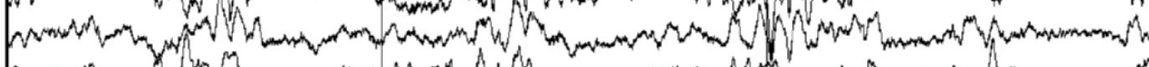

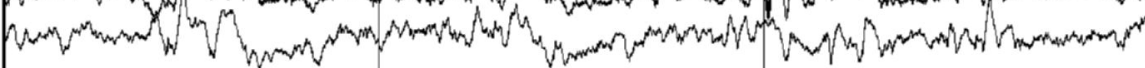



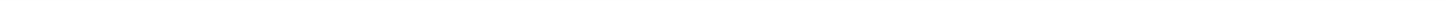